\title{
An expectancy model of Chinese-American differences in conflict-avoiding
}

\author{
Ray Friedman ${ }^{1}$, Shu-Cheng \\ $\mathrm{Chi}^{2}$, Leigh Anne Liu ${ }^{3}$ \\ ${ }^{1}$ Owen Graduate School of Management, \\ Vanderbilt University, Nashville, TN, USA; \\ ${ }^{2}$ Department of Business Administration, \\ National Taiwan University, Taipei, Taiwan; \\ ${ }^{3}$ Robinson College of Business, Georgia State \\ University, Atlanta, GA, USA
}

\author{
Correspondence: Ray Friedman, Owen \\ Graduate School of Management, \\ Vanderbilt University, 401 21st Avenue \\ South, Nashville, TN 37203, USA. \\ Tel: + 1615322 3992; \\ Fax: + 1615352 2414; \\ E-mail: Ray.Friedman@Owen. \\ Vanderbilt.Edu
}

\begin{abstract}
This paper develops an expectancy model for Chinese-American differences in conflict-avoiding, and tests this model using a scenario study with respondents from Taiwan and the US. Our results show that a higher Chinese tendency to avoid conflict is explained by higher Chinese expectations that direct conflict will hurt the relationship with the other party, and by greater concern for the other party among Chinese. It is not, however, explained by differences in the expected career costs/benefits of good/bad relations with others. Also, Chinese are more sensitive to hierarchy than Americans, so that avoiding is heightened more for Chinese than for Americans when the other party is of higher status. Qualitative results suggest that Chinese-American differences in time frames may also explain differences in avoiding. Implications for businesses and management are suggested.
\end{abstract}

Journal of International Business Studies (2006) 37, 76-9l.

doi: 10. I 057/palgrave.jibs.8400 172

Keywords: culture; conflict; avoiding; Chinese; guanxi

\section{Introduction}

With the rise of greater China as a major economic power (Child and Tse, 2001), and the growth of Western-Chinese business contacts, it becomes increasingly important to understand Chinese-Western cultural differences. One of the most commonly cited issues in cases about foreign companies in joint ventures with Chinese companies is differences in how conflict is managed and, in particular, a Chinese tendency to avoid conflict (e.g., Dyer and Song, 1997; Everatt et al., 1999). Western managers report great frustration when their Chinese colleagues do not approach differences openly and directly (and, we expect, the reverse frustration is reported by Chinese business people).

Given the centrality of avoiding conflict as an impediment to Western-Chinese business relationships, it is critical to be able to understand more clearly why this difference exists across cultures. First, as Chinese and Americans move into each other's working cultures, it helps to know how likely it is that conflict management styles will converge. If styles are triggered by deeply held values, then those styles are not likely to change; if styles are triggered by situational conditions, then a change of context (an American being in a Chinese cultural context, or vice versa) will likely change styles and diminish cross-cultural differences. Second, what factors drive avoiding behaviors may provide clues as to exactly what specific avoiding tactics are most likely to be prevalent. As Tjosvold
Received: 18 December 2002

Revised: 24 January 2005

Accepted: 18 May 2005

Online publication date: 27 October 2005 
and Sun (2002) point out, people sometimes avoid by 'conforming' and sometimes by 'working around' others. They suggest that the motivations for avoiding can affect which tactic is used. Third, modern businesses in China, Taiwan, Singapore, and other East Asian countries may want to encourage more direct expression of differences than has traditionally occurred. While there is evidence that Chinese can engage in constructive controversy (Tjosvold et al., 2003), it may not be productive if, as Bond and Hwang (1986) suggest, Chinese 'make more conforming shifts publicly but actually change their private beliefs less than American[s]' (p. 257).

\section{Theory}

\section{Conflict styles and far eastern cultures}

Avoiding as a general approach to managing disputes is seen as much more common in East Asian cultures than in Western cultures. Ohbuchi and Takahashi (1994), who define avoiding as 'refusing both overt recognition of a conflict and engagement in any active action toward its resolution' (p. 1347), found in their study of American and Japanese students that Japanese use an avoiding strategy $48 \%$ of the time, whereas Americans use this strategy $22 \%$ of the time. Bond and Hwang (1986) report similar patterns among Chinese:

\footnotetext{
Chinese strategies for resolving these conflicts... are characterized by strategies geared to short-circuit open conflict the use of indirect language, middlemen, face-saving ploys, a long-range view, flexibility, and so on. Strategies such as open debate, which require direct confrontation, are avoided (p. 262)
}

Morris et al. (1998) find that Chinese are more likely to avoid than Americans, whereas Americans are more likely to use a competitive or dominating strategy than Chinese, which reproduces a similar finding by Trubinsky et al. (1991). Our question is: Why does this difference occur? Before we proceed to analyze this question, we hypothesize:

H1: Chinese managers are more likely than Americans to use a more conflict-avoiding approach to managing disputes.

Central driver: the importance of the relationship Studies of conflict-avoiding in East Asian cultures focus heavily on the importance of relationships. Ohbuchi and Takahashi (1994) argue that Japanese are more concerned than Americans about maintaining a positive relationship with others. Despite the fact that Japanese in their study thought that engaging with others about problems would be more productive than avoiding, doing so was also seen as very risky - relationships may be damaged, and social harmony disrupted. For a collectivist culture (Triandis, 1995), they argue, maintaining social harmony and relationships is paramount. A similar point is made by Bond and Hwang (1986), who argue that, for Chinese, the most important factor is social order and interpersonal harmony. Although there is agreement over the importance of relationships in understanding East-West differences in conflict styles, it is not clear exactly how relationships have this effect.

\section{An expectancy model of conflict and relationships} To tease apart several ways in which relationships might be influential, we draw on expectancy theory (Vroom, 1964) in the same way that Leung (1987) did when studying Chinese and American preferences for binding $v s$ non-binding approaches to dispute resolution. Leung asked whether these differences were due to Chinese-American differences in valuing the outcome of a dispute resolution process (reduced animosity between the parties) or to differences in belief that a given dispute resolution approach would be effective at achieving the desired outcome of reduced animosity. The same logic, and questions, can be applied to conflict avoidance. Is conflict avoided more among Chinese because they value relationship outcomes more highly than Americans, or because they see conflict avoidance (or direct conflict) as more likely to generate (or damage) those preferred relationship outcomes? In addition, we can think of some outcomes as intrinsic and others as extrinsic (Porter and Lawler, 1968). Are differences in valuing relationships across cultures due to differences in inherent concern for the relationship, or due to differences in expectations that good relations with others are needed for instrumental purposes?

Thus, as shown in Figure 1, expectancy theory highlights three places where the motivation to avoid conflict may be different between Chinese and Americans. First, there may be differences in belief that being direct will hurt the relationships. This is an expectancy effect. Second, there may be differences in the belief that maintaining good relations 'pays off' in terms of material and political support. This is an instrumentality effect. Third, there may be differences in the degree to which Chinese and Americans are inherently concerned 


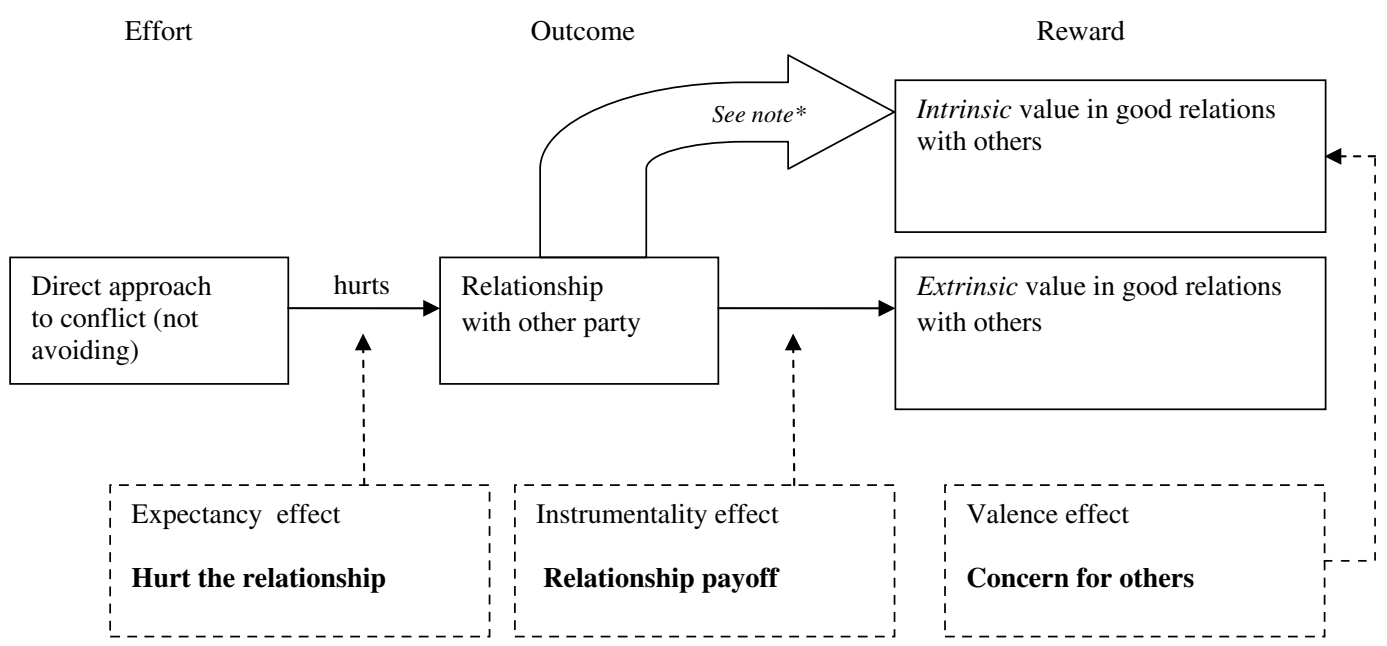

Figure 1 Expectancy model of conflict-avoiding. If relationships are intrinsically valued, the outcome-to-reward effect is automatic, so instrumentality has no role to play. (Measured variables are shown in bold.)

for others so that maintaining good relations is inherently valued. This is a valence effect.

\section{Expectancy: direct approach hurts relationship}

The first step in the expectancy model of conflictavoiding is the belief that taking a direct approach to conflict will hurt one's relationship with the other party. Yet there are reasons to believe that Chinese and Americans may differ in their prediction that such negative reactions will occur. According to Vollbrecht et al. (1997), in all cases 'confrontations are inherently face-threatening' because they affect 'feelings of competency and of being accepted by the confronter' (pp. 235-236). If Chinese anticipate the reactions of others more than do Americans, as Yang (1981) suggests, then they may be more aware than Americans of the general angry feelings that come from a direct approach to conflict, and of the potential costs to the relationship.

In addition, social norms may be so strongly against a direct approach that Chinese know that such behavior would be seen as inappropriate to the point that the relationship would be hurt. Confucian philosophy focuses on the principles of 'harmony' and 'developing one's moral potential'. Shenkar and Ronen (1987) describe harmony as 'an aspiration toward a conflict-free, group based system of social relations' (p. 266). Thus overt conflict disrupts harmony. In order to achieve harmony, people must follow correct behavior, or ' $l i$ ', which is behavior appropriate to one's role (Bond and Hwang, 1986)). Correct behavior includes controlling overt expressions of thoughts and emotions, so that 'the cultivated person strives to maintain self-control regardless of the situation and thus conforms to the ideal of xinpinqihe - 'being perfectly calm" (Shenkar and Ronen, 1987, 267).

As a result of Chinese norms, and expectations of negative responses to overt conflict, a direct or confrontational approach among Chinese is more likely to be seen as a threat by one party. Avoiding may be preferred in Chinese culture because there is a higher chance that a more direct approach will be interpreted as aggression, threatening the relationship.

H2: Chinese are more likely to expect that a direct approach to conflict management (i.e., not avoiding) will hurt the relationship with the other party.

H3: Higher conflict avoidance among Chinese compared with Americans is a result of Chinese expecting that a direct approach to conflict (i.e., not avoiding) will hurt the relationship with the other party.

\section{Instrumentality: relationship payoff}

From an instrumentality perspective, the implicit question that governs choice of conflict style is: What are the costs and benefits of taking a direct $v s$ an indirect approach to conflict? Assuming for the moment that direct conflict is more likely to cause disruptions in a relationship (as discussed above) is a disruption in the relationship likely to be very damaging? Whereas it is universally found that people treat those who are out-group to themselves 
worse than those who are in-group to themselves (Tajfel, 1978; Farwell and Weiner, 1996), this pattern is more pronounced within collectivist cultures such as Chinese culture (Leung and Bond, 1984; Zhou and Martocchio, 2001). The practical importance of relationships is well recognized within Chinese culture, as is seen in the concept of guanxi. Farh et al. (1998) point out that the 'tendency to treat people differently on the basis of one's relationship with them is why Guanxi is of such importance in Chinese societies' (p. 473). Having a bad or weak relationship with people can have enormous costs for Chinese, whereas being on good terms with them can lead to enormous rewards, even though those rewards may not be as immediate as would occur in the West (Hwang, 1987). Thus what determines avoiding in Chinese culture is a social environment that rewards and punishes strong and weak relationships more aggressively than other societies.

H4: In the context of managing disputes, Chinese are more likely to see a higher payoff from good relations with others ('relationship payoff') than Americans.

H5: Higher conflict avoidance among Chinese compared with Americans is a result of Chinese seeing greater payoff from good relations with others ('relationship payoff') than Americans.

\section{Valence: concern for others}

An alternative view is that Chinese care inherently about how others are treated. It may be that crosscultural differences in the importance of relationships do not come from their utilitarian benefits, but from inherent differences in Chinese and American values. Bond and Hwang (1986) review research showing that, from a very early age, Chinese children are more likely to be attracted to peers who maintain harmonious relationships, whereas American children are more likely to be attracted to peers who assert themselves through joking and games. Indeed, Hsu (1971) argues that the very concept of person in Chinese culture (ren) is not of an individual person, but of 'the individual's transactions with his fellow human beings' (p. 29). Thus concern about relationships with others is embedded deeply into Chinese culture.

H6: In the context of managing disputes, Chinese have higher levels of 'concern-for-others' than Americans do.
H7: Higher conflict avoidance among Chinese compared with Americans is a result of Chinese having higher levels of 'concern-for-others' than Americans do.

\section{Concern for authority as a moderator of expectancy and instrumentality effects}

While we expect there to be general patterns of Chinese-American differences in avoiding, some contexts may enhance or diminish these differences. One factor that might be especially important is the status of the person with whom there is a conflict. Chinese are known to be higher than Americans in power distance (Hofstede, 2001), and tend more than Americans to look to those higher in the hierarchy to resolve conflicts (Tinsley and Brett, 2001). Whereas there is a focus within American culture on egalitarianism (e.g., Barry, 2001), the emphasis within Chinese culture is on respect for authority (e.g., Confucius (Lau, trans., 1998)). We expect these factors to affect two elements of expectancy theory.

First, consider the effects of authority on the instrumentality effect. Given the higher level of respect for authority in Chinese culture, hierarchical control in Chinese organizations is much stronger (Quanyu et al., 1997) than in American organizations. As a result, bosses are likely to have a great ability and inclination to reward or punish those who are not on good terms with them. As a result, we expect that American-Chinese differences in relationship payoff will be especially large when the other party is a boss (rather than a peer). Second, consider the effects of authority on the expectancy effect (that direct approaches to conflict are likely to hurt relationships). Vollbrecht et al. (1997) point out that confrontations can be even more threatening if the person doing the confronting is higher status. Exactly how a confrontation is made (i.e., the degree of sensitivity shown to the other party's face) will be more important the higher the status of the individual initiating the confrontation. This pattern was confirmed empirically in Vollbrecht et al.'s (1997) study: perceptions of a disputant's 'face-sensitivity' were affected heavily by the style used, but only when that person was of high status. Greater status differentiation heightens the sensitivity of the message receiver to the style of the message sender. As Chinese are generally higher in 'power distance' than Americans (Hofstede, 1980, 2001), they experience greater status differentiation and a greater sense that others are authority figures. This 
should amplify the degree to which Chinese expect more than Americans that a direct approach to conflict will damage the relationship. Third, turning to valence effect, we see no reasons why this would be amplified by hierarchy in Chinese culture. If the concern is truly based on caring about the other person - not the benefits or costs he or she can impose - then it should not matter if that person is powerful or not. These relationships are shown in Figure 2.

H8: When a dispute is with someone of higher authority (e.g., a boss), Chinese-American differences in 'hurt relationship' and 'relationship payoff' will be greater.

If Hypothesis 8 holds true, and hierarchy amplifies Chinese-American differences in perceived relationship payoffs and concern that being direct will hurt the relationship, then, following the expectancy model, these differences should amplify differences in conflict-avoiding.

H9: Chinese preference for avoiding compared with Americans is stronger when a dispute occurs with someone of higher authority, such as a boss.

H10: The effect of authority on Chinese-American differences in conflict-avoiding is mediated by 'hurt relationship' and 'relationship payoff'.

In addition to these hypotheses about the role of authority, it is important to check for all prior hypotheses whether they hold both when the conflict is with a superior and when the conflict is with a colleague. If Hypotheses 2-7 are supported for only one condition, then the generalizability of the findings will be limited. If they are supported for both conditions, then this will show that the findings are more robust.

\section{Methods}

Our hypotheses were tested by presenting to Chinese and American participants a conflict scenario, and asking them how they would respond to that scenario. We chose this methodology because cross-cultural researchers have suggested that this is a useful method for enhancing crosscultural validity (Peng et al., 1997).

\section{Subjects}

In this paper we use the term 'Chinese' from a cultural perspective. This term incorporates not only Chinese living in mainland China, but also 'overseas Chinese' (Hofstede, 1993) in Taiwan, Hong Kong, Singapore, and other areas of southeast Asia. Participants were solicited through the MBA and Executive MBA programs at one university in the US and through the Executive MBA program at one university in Taiwan. Subjects in the US were paid $\$ 15$ to participate, and subjects in Taiwan were given a gift worth about $\$ 10$. The average age for the US sample was 31.9 compared with 37.5 in the Chinese sample. Given this difference, we control for age, experience, and rank in all our analyses. We had 162 Chinese participants and 146 American participants. The US sample had $71.4 \%$ males, compared with $57.4 \%$ in the Chinese sample. Therefore we also controlled for sex.

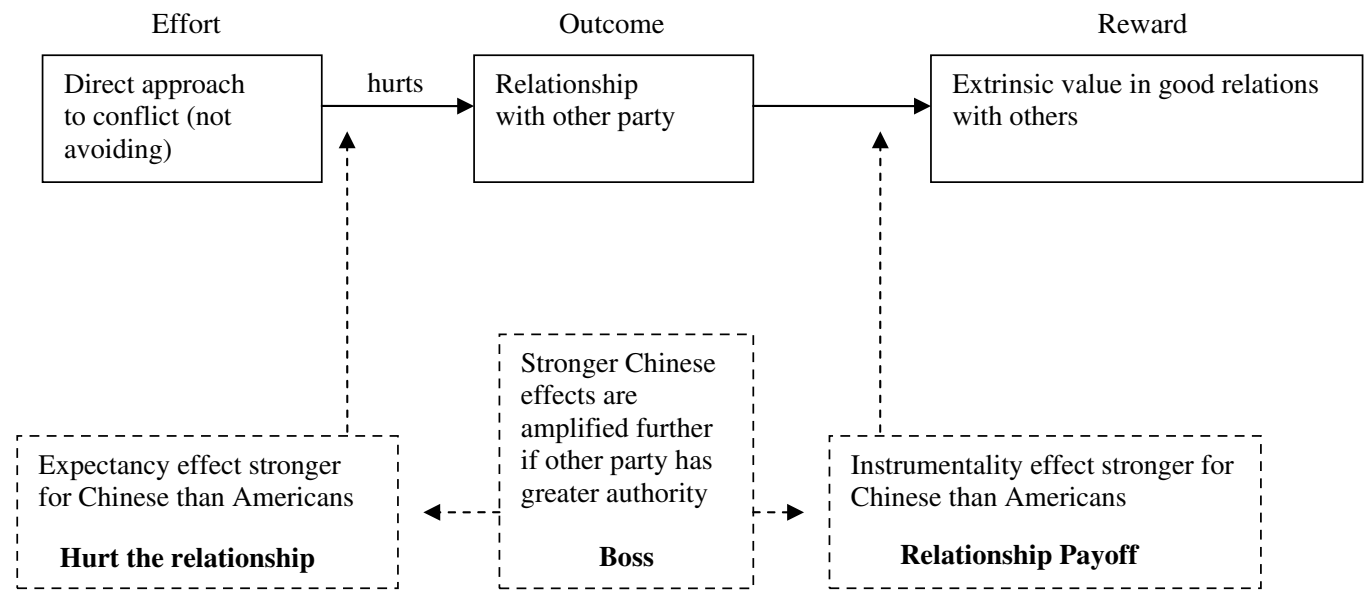

Figure 2 Moderating effects of boss on cross-cultural expectancy effects. (Measured variables are shown in bold.) 
We conducted a method check that the samples had values characteristic of their culture (Brett et al., 1997). We used three measures of cultural values: societal conservatism (Schwartz, 1992; Morris et al., 1998), collectivism (Triandis, 1995), and power distance (Hofstede, 1980; Kirkman and Shapiro, 2001). The Chinese in our sample were more socially conservative than the Americans $(M=5.31$, s.d. $=0.87$ for Chinese; $M=4.85$, s.d. $=0.82$ for Americans, $F[1,307=22.89], \quad P<0.001)$. The Chinese sample valued power distance more than did the Americans $(M=3.98$, s.d. $=1.08$ for Chinese; $M=3.23$, s.d. $=0.82$ for Americans, $\mathrm{F}[1,307=48.35]$, $P<0.001)$. The Chinese in our sample valued collectivism more than did the Americans $(M=5.15$, s.d. $=0.68$ for Chinese; $M=4.92$, s.d. $=0.61$ for Americans, $\mathrm{F}[1,307]=10.08, P<0.01)$.

\section{Scenario}

The scenario was adapted from one commonly used in justice research (see Davidson and Friedman, 1998), where a person has an idea that is 'stolen' by someone else during a meeting (i.e., presented as their own idea). Respondents were asked to put themselves in the role of the person whose idea was stolen (by a person called 'Chris Roberts' in the English version, and 'Zan U-Lin' in the Chinese version). We intentionally kept the name genderneutral, to avoid issues related to differential treatment of men and women in the two cultures. We also checked to make sure that our scenario followed the two principles of scenario creation used by Peng et al. (1997):

(1) The situation had to be possible in both cultures.

(2) The behavioral options had to be specified, but would not be seen as absurd or bizarre to the participants from either culture.

We created two versions of this scenario. In one version, the person who stole the idea is one's boss. In the other version, the person who stole the idea is a colleague.

One major concern was whether this scenario would generate equivalent levels of anger or injustice among Americans and Chinese. We examined the responses from the first surveys we received from the US $(n=38)$ and Taiwan $(n=30)$, in order to compare their responses on four items that assess feelings of anger and injustice (e.g., 'After this episode, I would feel anger,' and 'I would feel very upset knowing what had happened'). Mean American and Chinese responses were vir- tually identical. We concluded that, although we cannot be sure that the scenario is interpreted exactly the same way in both cultures, it did engender equivalently high levels of anger. However, to make sure that unequal feelings of anger or injustice did not drive our results, we added a measure of those feelings (discussed below) as controls in all analyses. This turned out to be necessary because, after the full sample was collected, there were some small $\left(\eta^{2}=0.04\right)$ but significant cross-cultural differences in the 'upset' scale.

\section{Measures}

Following the scenario, respondents were given a set of items using a 1-7 Likert scale, and an openended question asking how they would respond to this situation. All scales (except for avoiding and the values scales) were created specifically for this study, as there did not exist scales for most of our concepts. For scale development, we referred to procedures recommended by DeVellis (1991). In each case, items following a set of instructions were factor-analyzed to ensure that items loaded together, and scales alphas were calculated to assess reliability.

The sections and the phrasing of the instructions were organized carefully to separate out the effects we were analyzing. The first items following the scenario were ones designed to assess participants' sense of how upset they would be to face this situation. This was done first, to get a clean measure of initial subject responses. See Table 1 for means, standard deviations, and scale reliabilities.

Following these items, we asked two open-ended questions: 'If you were in this situation, what would you do after the meeting?' followed by 'What other possibilities might you consider? List as many or few as come to your mind.' In order to get a quantitative assessment of the participant's initial response to the conflict, we adapted Rahim's (2000) measures of Avoiding, Dominating, and Integrating (given the nature of the scenario, Accommodating and Compromising did not make sense). Exploratory factor analysis results led to slight modifications of the scales. We retained four items for the 'avoiding' scale (e.g., 'I would avoid an encounter with Roberts over this situation' and 'I would firmly present my concerns to Roberts' (R)).

At this point, we asked on the survey: 'While some of you may have chosen approaches that were more or less direct, what would happen if you approached the conflict directly (i.e., raised the issue 
Table 1 Means, standard deviations, scale reliabilities, and correlations

\begin{tabular}{|c|c|c|c|c|c|c|c|c|c|c|c|c|}
\hline Variable & Mean & s.d. & 1 & 2 & 3 & 4 & 5 & 6 & 7 & 8 & 9 & 10 \\
\hline 1. Age & 34.8 & 7.8 & - & & & & & & & & & \\
\hline 2. Sex $($ male $=1$, female $=2)$ & 1.36 & 0.48 & -0.15 & - & & & & & & & & \\
\hline 3. Experience & 3.54 & 1.60 & 0.69 & -0.13 & - & & & & & & & \\
\hline 4. Rank & 3.18 & 1.46 & 0.38 & 0.37 & 0.37 & - & & & & & & \\
\hline 5. Upset & 5.40 & 1.02 & -0.22 & 0.03 & -0.20 & -0.10 & $(0.72)$ & & & & & \\
\hline 6. Chinese $(A m=0, C h=1)$ & 0.53 & 0.50 & 0.36 & 0.15 & 0.40 & 0.04 & -0.33 & - & & & & \\
\hline 7. Hurt relationship & 4.45 & 1.15 & 0.07 & 0.08 & 0.14 & 0.03 & 0.03 & 0.32 & $(0.81)$ & & & \\
\hline 8. Relationship payoff & 4.61 & 0.80 & 0.10 & 0.08 & 0.04 & 0.14 & 0.17 & 0.04 & 0.45 & $(0.71)$ & & \\
\hline 9. Concern for others & 3.48 & 1.01 & 0.24 & -0.07 & 0.11 & -0.03 & -0.42 & 0.42 & 0.19 & -0.06 & $(0.76)$ & \\
\hline 10. Avoiding & 3.16 & 1.59 & 0.24 & 0.07 & 0.32 & -0.03 & -0.44 & 0.61 & 0.39 & 0.11 & 0.52 & $(0.84)$ \\
\hline
\end{tabular}

Correlations greater than 0.12 are significant at the 0.05 level, two-tailed. Those greater than 0.14 are significant at the 0.01 level. Those greater than 0.18 are significant at the 0.001 level. Scale reliabilities are on the diagonal.

with your boss/colleague, Chris Roberts)?' Following were 10 items designed to assess whether the respondent believed that the relationship with Roberts would be damaged if a direct approach to conflict management was used. These items were used to create a scale for 'hurt relationship'. Sample items included 'My relationship with Roberts would be damaged', 'Roberts would feel insulted', and 'Roberts would respect me for being direct' (R). Each item asked about the expected quality of the relationship after approaching the conflict directly (i.e., not avoiding).

The next section in the survey asked respondents to consider how they would feel if their relationship with their boss/colleague was damaged. One set of six items addressed the instrumental costs of a damaged relationship. These items were used to create a scale for 'relationship payoff'. Some items from this scale were 'Roberts would retaliate against me' and 'Roberts would no longer provide support for me at work.' Each item asked about the practical consequences of a bad relationship. Another set of eight items addressed the intrinsic value that the respondent placed on having a good relationship with Roberts. These items were used to create a scale for 'concern for others'. Some items from this scale were 'I would feel a great sense of personal loss if my relationship with Roberts was damaged' and 'If Roberts feels upset, that is Roberts' problem (R)'. Each item was designed to assess whether the subject would feel personally upset if the relationship was hurt. To confirm that all five scales measured separate constructs, we performed a CFA, which showed a good fit for the five-factor model $\quad(\mathrm{GFI}=0.929, \quad \mathrm{IFI}=0.929, \quad \mathrm{CFI}=0.925$, RMSEA $=0.044)$. To check for possible autocorrelations, we conducted Durbin-Watson tests among these scales. The coefficient, $d$, ranged from 1.87 to 2.09, allowing us to reject autocorrelation (Kennedy, 1998).

Lastly, we included demographic questions about age, sex, organizational level, and experience with work. All materials were written in English, translated into Chinese, and back-translated into English (Brislin et al., 1973).

\section{Results}

\section{Quantitative results}

The first step was to examine whether there were significant differences in conflict-avoiding between the Chinese and American samples, as expected. To do so, we regressed 'avoiding' on a dummy variable for Chinese (Chinese $=1$, American=0), controlling for sex, experience, age, organizational level, and (most importantly) 'Upset'. This last variable showed the degree to which the individual was angry as a result of the incident. The regression model shows that Chinese report using more avoiding than Americans (see Table 2, Model 1), supporting Hypothesis 1.

Regressions testing Hypotheses 2-7 were run for the boss and colleague conditions separately, and for both together. In all cases the effects were nearly identical for these analyses, so for clarity and parsimony we report only the results from the analyses using the combined sample. Regression models testing Hypotheses 2, 4, and 6 are shown in Table 2. Chinese were significantly higher in 'hurt relationship' (Model 2) and 'concern for others' (Model 4), supporting Hypotheses 2 and 6. However, Chinese was not a significant predictor of 'relationship payoff' (Model 3), so that Hypothesis 4 is not supported. 
Table 2 Regression models

\begin{tabular}{|c|c|c|c|c|c|c|c|c|}
\hline Dependent variables & Avoiding & $\begin{array}{c}\text { Hurt } \\
\text { relationship }\end{array}$ & $\begin{array}{c}\text { Relationship } \\
\text { payoff }\end{array}$ & $\begin{array}{c}\text { Concern for } \\
\text { others }\end{array}$ & Avoiding & Avoiding & Avoiding & Avoiding \\
\hline Model & (1) & (2) & (3) & (4) & (5) & (6) & (7) & (8) \\
\hline Hypothesis tested & $\mathrm{H} 1$ & $\mathrm{H} 2$ & $\mathrm{H} 4$ & H6 & $\mathrm{H} 3$ & H5 & $\mathrm{H} 7$ & - \\
\hline Overall $F$ & 33.95 & 7.23 & 4.35 & 16.49 & 53.94 & 47.05 & 51.56 & 46.47 \\
\hline Model $R^{2}$ adj. & 0.40 & 0.15 & 0.06 & 0.24 & 0.49 & 0.43 & 0.47 & 0.56 \\
\hline d.f. & 6290 & 6290 & 6290 & 6290 & 7289 & 7289 & 7289 & 9287 \\
\hline Variables & $\beta$ & $\beta$ & $\beta$ & $\beta$ & $\beta$ & $\beta$ & $\beta$ & $\beta$ \\
\hline \multicolumn{9}{|l|}{ Controls } \\
\hline Age & -0.05 & -0.07 & 0.12 & 0.06 & -0.02 & -0.07 & -0.06 & -0.05 \\
\hline Sex & -0.04 & 0.02 & 0.02 & 0.00 & -0.05 & -0.04 & -0.04 & -0.05 \\
\hline Experience & $0.15^{*}$ & 0.07 & -0.09 & -0.07 & $0.12^{*}$ & $0.16^{\star \star}$ & $0.17^{* *}$ & $0.15^{\star *}$ \\
\hline Rank & -0.12 & 0.04 & $0.16^{*}$ & -0.07 & $-0.14^{\star *}$ & $-0.15^{\star *}$ & $-0.10^{\star}$ & $-0.12^{\star *}$ \\
\hline Upset & $-0.20^{\star *}$ & $0.17^{* * *}$ & $0.24^{* * *}$ & $-0.27^{* * *}$ & $-0.26^{\star \star *}$ & $-0.25^{* * *}$ & $-0.12^{\star \star}$ & $-0.19 * * *$ \\
\hline Chinese $($ American $=0$, Chinese $=1)$ & $0.53^{* * *}$ & $0.37^{* * *}$ & 0.08 & $0.38^{\star \star *}$ & $0.41^{* * *}$ & $0.51^{* * *}$ & $0.41^{* * *}$ & $0.32^{\star * *}$ \\
\hline \multicolumn{9}{|l|}{ Expectancy model predictors } \\
\hline Hurt relationship & & & & & $0.32^{* \star *}$ & & & $0.27^{* * *}$ \\
\hline Relationship payoff & & & & & & $0.17^{* \star *}$ & & 0.05 \\
\hline Concern for others & & & & & & & $0.30^{\star * *}$ & $0.27^{* * *}$ \\
\hline
\end{tabular}

Hypotheses 3, 5, and 7 predict mediating effects, and therefore require the method proposed by Baron and Kenny (1986). To show that the effect of $A$ on $C$ occurs through $B$, you need to (a) show that A predicts $C$, (b) show that B predicts $C$, and (c) show that when $B$ is added to the model showing that A predicts C, B is significant while the effect of $\mathrm{A}$ is eliminated (full mediation) or reduced (partial mediation). In our case, we have already shown (Model 1) that Chinese predicts conflict-avoiding (step a). Steps b and c are shown in Models 5, 6, and 7 of Table 2, where each mediator is added to Model 1. In these models we can see whether the effect of the mediator on avoiding is significant, and whether adding this mediator reduces the significance of the coefficient for Chinese.

These results show that 'hurt relationship' and 'concern for others' both partially mediate the effect of Chinese on conflict-avoiding, supporting Hypotheses 3 and 7. Model 5 in Table 2 shows that 'hurt relationship' is significant, and the addition of this variable to Model 1 reduces the beta for Chinese also from 0.53 to 0.41 . Model 7 in Table 2 shows that 'concern for others' is significant, and the addition of this variable to Model 1 reduces the beta for Chinese from 0.53 to 0.41 . Thus partial mediation is shown. 'Relationship payoff', however, does not have the same effect. Adding 'relationship payoff' to the base model (as shown in Model 6) has almost no effect on the beta for Chinese (the change is from 0.53 to 0.51 ), and Chinese does not predict relationship payoff (Model 3). Therefore Hypothesis 5 is rejected. Lastly, looking at Model 8, which includes all three mediating variables, we can see that 'concern for others' and 'hurt relationship' are both significant predictors of 'avoiding', whereas 'relationship payoff' is no longer significant.

We tested Hypothesis 9, that difference between Chinese and American avoiding was greater when the harm-doer was the boss than when the harmdoer was a colleague, by adding an interaction effect for Chinese $\times$ Boss $(\beta=0.28, \quad P<0.05)$, as shown in Table 3, Model 3. This interaction effect was statistically significant. A graph showing the interaction effect is displayed in Figure 3. Following Aiken and West (1991), points were calculated using values 1 s.d. above and below the mean. In both conditions (boss and colleague) Chinese were much more likely to avoid than Americans, but the difference was smaller in the colleague condition than the boss condition.

Next, we examined whether the Boss $\times$ Chinese interaction predicted 'relationship payoff' and 'hurt relationship' (our potential mediator variables) as described in Hypothesis 8 (see Table 3, Models 1 and 2). The interaction had a very clear and strong effect on 'hurt relationship' - concern that the 
Table 3 Regression models for interaction effects

\begin{tabular}{|c|c|c|c|c|c|}
\hline Dependent variables & Relationship payoff & Hurt relationship & Avoiding & Avoiding & Avoiding \\
\hline Model & (1) & (2) & (3) & (4) & $(5)$ \\
\hline Hypothesis tested & $\mathrm{H} 8$ & $\mathrm{H} 8$ & $\mathrm{H} 9$ & $\mathrm{H} 10$ & $\mathrm{H} 10$ \\
\hline Overall $F$ & 5.53 & 8.17 & 27.00 & 25.78 & 32.78 \\
\hline Model $R^{2}$ adj. & 0.11 & 0.16 & 0.41 & 0.43 & 0.49 \\
\hline d.f. & 8288 & 8288 & 8288 & 9287 & 9287 \\
\hline Variables & $\beta$ & $\beta$ & $\beta$ & $\beta$ & $\beta$ \\
\hline \multicolumn{6}{|l|}{ Controls } \\
\hline Age & 0.11 & -0.08 & -0.05 & -0.07 & -0.03 \\
\hline Sex & 0.05 & 0.04 & -0.03 & -0.03 & -0.04 \\
\hline Experience & -0.09 & 0.07 & $0.15^{*}$ & $0.16^{\star \star}$ & $0.13^{*}$ \\
\hline Rank & $0.16^{*}$ & 0.04 & $-0.12^{\star \star}$ & $-0.15^{\star \star}$ & $-0.13^{\star *}$ \\
\hline Upset & $0.23^{* * *}$ & $0.17^{* *}$ & $-0.21^{\star * *}$ & $-0.25^{\star \star *}$ & $-0.26^{\star * *}$ \\
\hline Chinese $($ American $=0$, Chinese $=1$ ) & 0.27 & $0.86^{\star * *}$ & $0.78^{\star \star \star}$ & $0.74^{* * *}$ & $0.51^{\star \star \star}$ \\
\hline Boss & $-0.28^{* * *}$ & $-0.25^{* * *}$ & $-0.17^{\star \star}$ & $-0.13^{*}$ & -0.09 \\
\hline Chinese $\times$ boss & 0.21 & $0.55^{\star *}$ & $0.28^{*}$ & $0.25^{*}$ & 0.11 \\
\hline Relationship payoff & & & & $0.15^{\star *}$ & \\
\hline Hurt relationship & & & & & $0.31 * * *$ \\
\hline
\end{tabular}

${ }^{*} P<0.05,{ }^{* *} P<0.01,{ }^{* * *} P<0.001$ (all two-tailed).

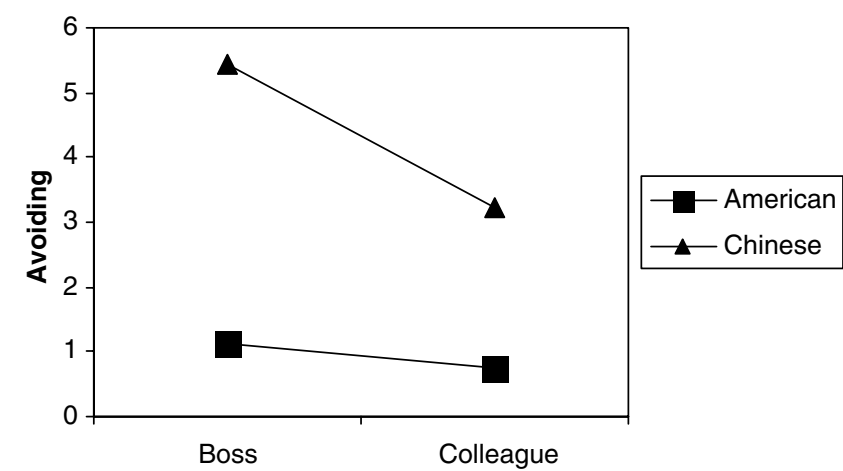

Figure 3 Interaction of culture and authority on avoiding.

other party might react negatively to a direct approach to conflict is exacerbated when that person is a boss more for Chinese than for Americans (see Table 3, Model 2, and Figure 4). For Chinese, a direct approach with those in authority is seen as especially unproductive. The interaction had no effect on 'relationship payoff' (Table 3, Model 1). These results show partial support for Hypothesis 8 .

To test for Hypothesis 10, that 'hurt relationship' and 'relationship payoff' would mediate the effect of the Boss $\times$ Chinese interaction terms, we added each of these potential mediators to Model 3 of Table 3, following the Baron and Kenny (1986)

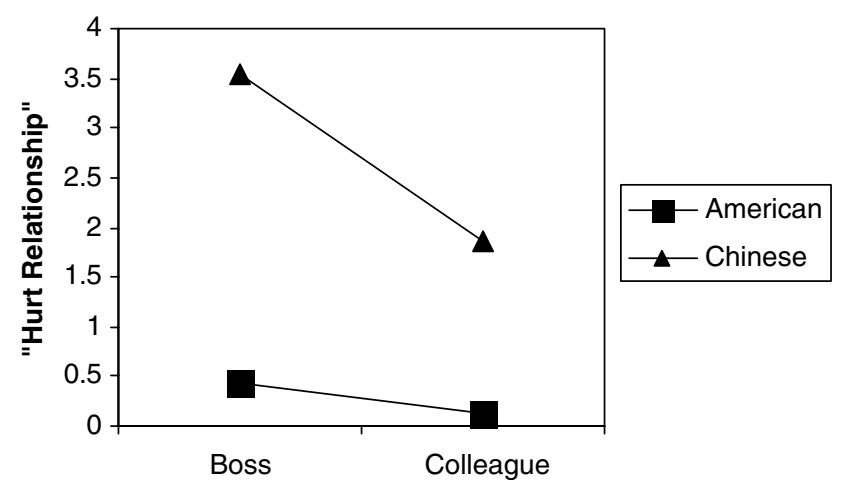

Figure 4 Interaction of culture and authority on 'hurt relationship'.

method discussed above. Adding 'hurt relationship' (Model 5) eliminates the significance of the Boss $\times$ Chinese interaction, and reduces the coefficient from 0.28 to 0.11 , showing full mediation. Adding 'relationship payoff' (Model 4) does not affect the significance of the Boss $\times$ Chinese interaction, nor does it reduce the coefficient size for the interaction. Chinese seem to be especially concerned that direct approaches to conflict-avoiding will hurt the relationship with the boss, and this appears to drive the overall tendency for Chinese to be more conflict-avoiding than Americans when dealing with those in positions of authority. 


\section{Qualitative results}

Each respondent was asked to describe at the beginning of the survey what he or she would do in the situation described. These items were then printed onto 3 in $\times 5$ in cards, and research assistants sorted the cards into categories that represented themes. They were asked to look for any common patterns among respondents, and cluster them accordingly. This was done separately for the Chinese and American responses. The Chinese responses were read, in Chinese, by two assistants who were fluent in Chinese. The American responses were read, in English, by two assistant who were fluent in English. Note that assistants were not only assigning cases to categories, but also creating the categories themselves. After these categories were created, the two assistants were asked to rank each type of response on a 1-7 scale from low to high on level of directness. There was a high rate of agreement between assistants in these evaluations. Using Spearman's rank-order correlation (Siegel and Castellan, 1988) to examine interrater reliability, we achieve scores of 0.81 for the Chinese sample and 0.75 for the American sample. In the few cases where there were differences of opinion, the raters got together to discuss their scores and decide what an appropriate score would be. The categories that emerged, and the percentage of respondents using each category of response, are reported in Appendix A. An analyses of the rankings of directness applied to these data revealed that the mean level of directness among Americans was 5.9 compared with 4.4 among Chinese. This difference was significant $(t=6.13$, $P<0.001)$.

More interesting than these overall effects is what these responses reveal about Chinese and American strategies for dealing with this type of conflict. On the American side, with nearly universal preference for being direct, the key question was how to be direct. Some Americans wanted simply to express their displeasure to Roberts, some also wanted also find out from Roberts why he had acted that way, and still others were concerned to only confront Roberts in private. There also seemed to be a lot of thought about whether to talk first with Roberts or first with Roberts' boss. So, there was some sensitivity to the other side - not wanting to embarrass Roberts, and wanted to listen to his or her view - and some concern about who should be talked to first. But the presumption seems to be that Roberts would be called to task for his behaviors.
By contrast, the Chinese respondents were just as nuanced and subtle in how they avoided conflicts (which is consistent with reports by Tjosvold and Sun, 2002), and how to manage their own frustration with the abuses that had occurred. While a sizeable subset of Chinese would in fact be just as direct as the Americans (with some wanting to approach Roberts directly and some wanting instead to go to his boss), there appeared among the Chinese a set of tactics that were not even considered by Americans. Many focused on a tactic we labeled 'do nothing right now but draw a lesson for future actions'. This included 'say nothing but collect more data on my own', and 'be calm, keep distance from the colleague who stole my idea, but be active and do more research on the plan'. This approach implies a longer time frame, where the concern is not immediate reward but patience and long-term success. Thus, for these Chinese respondents, there seems to be less concern than for Americans about the single incident described in the scenario, indicating that a driver of avoiding among Chinese may be the presence of a much longer time frame for thinking about events. This is consistent with Hofstede's (2001) finding that scores for 'long-term orientation' are much higher for Chinese from Hong Kong (96), Taiwan (87), and mainland China (118) than Americans (29), and suggests hypotheses that we have not considered in this research project, but which it would be useful to add to future research on conflict-avoiding in Chinese culture.

Another approach that Chinese took but Americans did not take is to 'support and cooperate'. This includes approaches such as 'I'll recognize the colleague's proposal, get to know what to do next, and add my suggestions' and 'I will provide suggestions to the boss on how to implement the plan.' Here, the approach seems to be one where individual ego is suppressed, and contribution to the greater good is emphasized. This tendency seems even stronger in the boss condition, where many Chinese simply wanted to congratulate the boss or try to learn what his or her next action would be. A related approach taken by a small number of Chinese is to 'feel angry' but do nothing. Here, there is explicit recognition of the fact that individual ego needs are suppressed. This indicates that a driver of avoiding among Chinese may be their focus on the needs of others and of the collective (which is consistent with our hypothesis about the 'concern for others' valence effect), but also gets at an issue that we have not explicitly 
addressed, which is suppression of one's own ego needs, or emotional self-control. This is another area that should be studied in the future.

\section{Discussion}

\section{Summary of major findings}

Our findings suggest that higher levels of avoiding among Chinese are a result of both expectancy and valence effects. That is, Chinese are more likely to believe that a direct approach to conflict will damage the relationship with the other party (an expectancy effect) and to show more concern for the other party (a valence effect). However, no support was found for the proposition that Chinese care more about relationships because those relationships, in turn, provide payoffs in terms of guanxi, favors, or the potential to be treated as an outsider if a relationship is damaged (the instrumentality effect). Whereas this may be surprising if we consider the prevalence of guanxi in Chinese society, it is not surprising if we consider how much American culture also values social networks. Baker (1994) points out the importance of social networks for managers, Kotter (1985) shows that social support is critical to get things done in corporations, and Kram (1988) highlights the importance of social networks for mentoring and career support. Thus social ties may be just as important in the US as they are in Chinese societies.

\section{Implications for tactics used}

One implication of these findings is that when Chinese avoid more than Americans, this added avoiding is likely to be made up of conforming tactics more than outflanking. Tjosvold and Sun (2002) argue that to the degree that a person avoids owing to a desire not to hurt one's interests, avoiding will take the form of 'outflanking', or working behind the scenes to get what you want. To the degree that the motivation to avoid is due to a desire to maintain harmony, then avoiding will take the form of 'conforming'. Our results suggest that, although outflanking is certain to occur among Chinese, it is not likely to be stronger among Chinese than among Americans. By contrast, given higher levels of concern for others among Chinese, conforming is likely to be more common among Chinese than among Americans. This conclusion matches those of Tjosvold and Sun's (2002) and our qualitative results reported above.

\section{Implications for change of style}

These results also have implications for whether Americans and Chinese are likely to be able to adopt each other's styles as they work together. If avoiding were a tactic driven primarily by the external benefits to be attained by maintaining good relations, as suggested by the instrumentality hypothesis, then behaviors would likely change quickly when the environment and its associated benefits changed. By contrast, if Chinese-American differences are anchored in terminal values, as suggested by the valence hypothesis, then change of environment is not likely to change behaviors. This is important because, as Pornpitakpan (1999) and Francis (1991) show, social attraction between members of different cultures is influenced by how much they are able to adapt to the norms and behaviors of the foreign culture. Our results suggest that Chinese-American differences in avoiding are likely to persist, even with time spent together, because there are fundamentally different levels of concern for the other party.

The one area of leverage for change, however, might be with the expectancy effect - the degree to which one believes that being direct will hurt the relationship. If Chinese can see that direct discussion of conflict does not hurt relationships as much within a Western cultural context, they might then change their style and be more willing to be direct in a Western context. However, the inverse may not be true for Americans. Learning that being direct hurts relationships more in Chinese culture could teach Americans to be less direct in Chinese cultural contexts, but this may not matter so much for Americans, given the lower level of inherent concern for relationships. Thus we would expect greater adaptation of Chinese to the Western context, than of Americans to the Chinese context.

\section{Implications for voice in Chinese organizations}

Our findings also indicate that Chinese are more likely to avoid conflict when the dispute is with someone in a position of authority, mainly because Chinese are more likely to believe that approaching a boss directly will hurt the relationship with that boss. This has implications for information flow in Chinese companies. Many scholars argue that it is important for employees to provide full and timely feedback when they see problems in a company (e.g., Nemeth and Staw, 1989; Dutton and Ashford, 1993), and one element of extra-role behaviors beneficial to organizations is the open expression of ideas and feedback to a company (Van Dyne and 
Lepine, 1998; Morrison and Phelps, 1999). The tendency for avoiding to be amplified by hierarchy among Chinese indicates that these desired behaviors may be especially hard to achieve with Chinese employees. Managers may need to take special efforts to signal an openness to direct conflict, or they may need to work around this constraint by ensuring that work teams include only individuals with similar status so that hierarchy does not amplify avoidance behaviors.

\section{Expectancy theory for conflict styles}

The expectancy model suggests that, in order to understand avoiding, you must look at people's motivations to avoid. Our results show that a careful examination of expectancy, instrumentality, and valence effects can make it clearer why some people avoid more than others. Any condition that changes one's expectation that direct conflict will hurt a relationship will also change the tendency to avoid. Chinese differ from Americans in that they are more likely to expect directness to hurt the relationship, but this effect can be diminished by factors that change that expectation. The more cooperative the goal (Tjosvold and Sun, 2002), and the more reasonable the other person (Morris et al., 2004), the less likely it is that being direct will hurt the relationship, making avoiding less necessary. Thus, despite a central tendency for Chinese to avoid more than Americans, the expectancy model highlights a source of within-culture variation in avoiding that must also be examined. This is important because - of course - Chinese do not always avoid and Americans are not always direct. More broadly, from a managerial perspective, if managers want to enhance open discussion of conflicts, they need to manage their employees' environment in such a way that employees do not perceive that open disagreements will damage relationships (see, e.g., Edmonson, 1999, on psychological safety in teams), breaking the first link in the expectancy model.

\section{Research implications}

For scholars, our findings point out that the emphasis placed on relationships in Chinese culture needs to be studied in more detail. Although relationships are central, a distinction needs to be made between relationships as ends in themselves and as a means to other ends, as discussed by Leung (1997), and care must be taken to see whether behaviors are driven more by expectancy, instrumentality, or valence effects. Our qualitative results also suggest new directions for research about conflict-avoiding. Whereas Americans appear to think with great subtlety about how to be direct, Chinese appear to think with great subtlety about how to avoid conflict. More work can be done to examine the wide array of tactics used both by Americans for being direct, and by Chinese for avoiding (as suggested by Tjosvold and Sun, 2002).

\section{Study limitations}

We should, however, point out some limitations of this study. First, we include samples of subjects from only one region within Western and Chinese cultures. Results could be different with American subjects from New York or California, or Chinese subjects from Shanghai or Singapore. Second, some of our scales have not been validated in prior research. This was necessary, in part, because this was a scenario study where we needed to assess reactions to the specific situation identified. We also need to be careful about interpreting our finding that 'relationship payoff' did not show significant differences between Americans and Chinese. There may be other ways in which the practical consequences of bad relationships are experienced differentially by Chinese and Americans. For example, it may be that cross-cultural differences exist in the reactions of people observing the conflict between the two parties, even though there are not differences in the expected reactions of the harm-doer. There may be a wider range of repercussions that we have not yet studied.

Despite these limitations, we contribute to the field of international business research by developing an expectancy model of conflict, and comparing the relative impact of expectancy, instrumentality, and valence as drivers of conflict avoiding. We also provide data on the effect of hierarchy on avoiding, and report qualitative results that suggest new avenues for research.

\section{Acknowledgements}

This project was funded by a grant from the National Science Council in Taiwan (NSC-89-2416-H-002-088) and support from the Owen Graduate School of Management, Vanderbilt University. We thank the two anonymous reviewers for their constructive comments and suggestions, and Kwok Leung, who helped us tremendously to sharpen and focus the paper. 


\section{References}

Aiken, L.S. and West, S.G. (1991) Multiple Regression: Testing and Interpreting Interactions, Sage: Newbury Park, CA.

Baker, W.E. (1994) Networking Smart: How to Build Relationships for Personal and Organizational Success, McGraw-Hill: New York.

Baron, R.M. and Kenny, D.A. (1986) 'The moderator-mediator variable distinction in social psychological research: conceptual, strategic, and statistical considerations', Journal of Personality and Social Psychology 51(5): 1173-1182.

Barry, B.M. (2001) Culture and Equality: An Egalitarian Critique of Multiculturalism, Harvard University Press: Cambridge, MA.

Bond, M.H. and Hwang, K.K. (1986) 'The Social Psychology of Chinese People', in M.H. Bond (ed.) The Psychology of the Chinese People, Oxford University Press: Hong Kong, pp: 213-266.

Brett, J.M., Tinsley, C.H., Janssens, M., Barsness, Z.I. and Lytle, A.L. (1997) 'New Approaches to the Study of Culture in Industrial/Organizational Psychology', in P.C. Earley and M. Erez (eds.) New Perspectives on International Industrial/organizational Psychology, New Lexington Press: San Francisco, pp: 75-129.

Brislin, R.W., Lonner, W.J. and Thorndike, R.M. (1973) Crosscultural Research Models, Wiley: New York.

Child, J. and Tse, D.K. (2001) 'China's transition and its implications for international business', Journal of International Business Studies 32(1): 5-21.

Confucius (Lau, D.C. trans.) (1998) Confucius: The Analects, Penguin: New York.

Davidson, M. and Friedman, R. (1998) 'When excuses don't work: the persistent injustice effect among black managers', Administrative Science Quarterly 43(1): 154-183.

DeVellis, R.F. (1991) Scale Development: Theory and Applications, Sage: Newbury Park, CA.

Dutton, J.E. and Ashford, S.J. (1993) 'Selling issues to top management', Academy of Management Review 18(3): 397-428.

Dyer, B. and Song, X.M. (1997) 'The impact of strategy on conflict: a cross-national comparative study of US and Japanese firms', Journal of International Business Studies 28(3): 467-493.

Edmonson, A. (1999) 'Psychological safety and learning behavior in work teams', Administrative Science Quarterly 44(4): 350-383.

Everatt, D., Slaughter, K. and Jie, Z. (1999) Alpha Gearing Systems, Shanghai Co., Ltd, Ivey Case \#9A99C014, Ivy Publishing, Richard Ivy School of Business, The University of Western Ontario: London, Ontario, Canada.

Farh, J.L., Tsui, A.S., Xin, K. and Cheng, B.S. (1998) 'The influence of relational demography and guanxi: the Chinese case', Organization Science 9(4): 471-488.

Farwell, L. and Weiner, B. (1996) 'Self-perceptions of fairness in individual and group contexts', Personality and Social Psychology Bulletin 22(9): 868-881.

Francis, J.N.P. (1991) 'When in Rome? The effects of cultural adaptation on intercultural business negotiations', Journal of International Business Studies 22(3): 403-428.

Hofstede, G. (1980) Culture's Consequences: International Differences in Work-related Values, Sage: Beverly Hills, CA.

Hofstede, G. (1993) 'Cultural constraints in management theories', Academy of Management Executive 7(1): 81-94.

Hofstede, G. (2001) Culture's Consequences: Comparing Values, Behaviors, Institutions, and Organizations Across Nations, Sage: Thousand Oaks, CA.

Hsu, F.L.K. (1971) 'A Hypothesis on Kinship and Culture', in F.L.K. Hsu (ed.) Kinship and Culture, Aldine: Chicago, pp: 3-30.

Hwang, K.K. (1987) 'Face and favor: the Chinese power game', American Journal of Sociology 92(4): 944-974.

Kennedy, P. (1998) A Guide to Econometrics, 4th edn., MIT Press: Cambridge, MA.

Kirkman, B.L. and Shapiro, D.L. (2001) 'The impact of cultural values on job satisfaction and organizational commitment in self-managing work teams: the mediating role of employee resistance', Academy of Management Journal 44(3): 557-569.
Kotter, J.P. (1985) Power and Influence: Beyond Formal Authority, Free Press: New York.

Kram, K.E. (1988) Mentoring at Work: Developmental Relationships in Organizational Life, University Press of America: Lanham, MD.

Leung, K. (1987) 'Some determinants of reactions to procedural models for conflict resolution: a cross-national study', Journal of Personality and Social Psychology 53(5): 898-908.

Leung, K. (1997) 'Negotiation and Reward Allocations Across Cultures', in P.C. Earley and M. Erez (eds.) New Perspectives on International Industrial/Organizational Psychology, The New Lexington Press/Jossey-Bass: San Francisco, pp: 640-675.

Leung, K. and Bond, M.H. (1984) 'The impact of cultural collectivism on reward allocation', Journal of Personality and Social Psychology 47(4): 793-804.

Morris, M.W., Leung, K. and lyengar, S.S. (2004) 'Person perception in the heat of the conflict: negative trait attributions affect procedural preferences and account for situational and cultural differences', Asian Journal of Social Psychology 7(2): 127-147.

Morris, M.W., Williams, K.Y., Leung, K., Larrick, R., Mendoza, M.T., Bhatnagar, D., Li, J., Kondo, M., Luo, J.L. and Hu, J.C. (1998) 'Conflict management style: accounting for crossnational differences', Journal of International Business Studies 29(4): 729-748.

Morrison, E.W. and Phelps, C.C. (1999) 'Taking charge at work: extrarole efforts to initiative workplace change', Academy of Management Journal 42(4): 403-419.

Nemeth, C.J. and Staw, B.M. (1989) 'The Tradeoffs of Social Control and Innovation in Groups and Organizations', in L. Berkowitz (ed.) Advances in Experimental Social Psychology, Vol. 22, Academic Press: New York, pp: 175-210.

Ohbuchi, K.Y. and Takahashi, Y. (1994) 'Cultural styles of conflict management in Japanese and Americans: passivity, covertness, and effectiveness of strategies', Journal of Applied Social Psychology 24(15): 1345-1366.

Peng, K., Nisbett, R. and Wong, N. (1997) 'Validity problems comparing values across cultures and possible solutions', Psychological Methods 2(4): 329-344.

Pornpitakpan, C. (1999) 'The effects of cultural adaptation on business relationships: Americans selling to lapanese and Thais', Journal of International Business Studies 30(2): 317-338.

Porter, L.W. and Lawler, E.E. (1968) Managerial Attitudes and Performance, Irwin-Dorsey: Homewood, IL.

Quanyu, H., Leonard, J. and Tong, C. (1997) Business Decision Making in China, International Business Press: New York.

Rahim, M.A. (2000) Managing Conflict in Organizations, 3rd edn., Quorum: Westport, CT.

Schwartz, S. (1992) 'Universals in the Content and Structure of Values: Theoretical Advances and Empirical Tests in 20 Countries', in M.P. Zanna (ed.) Advances in Experimental Social Psychology, Vol. 25, pp: 1-65, NY: Academic Press.

Shenkar, O. and Ronen, S. (1987) 'The cultural context of negotiations: the implications of Chinese interpersonal norms', Journal of Applied Behavioral Science 23(2): 263-275.

Siegel, S. and Castellan Jr, N.J. (1988) Nonparametric Statistics for the Behavioral Sciences, 2nd edn., McGraw-Hill: Boston.

Tajfel, H. (1978) Differentiation Between Social Groups: Studies in the Social Psychology of Intergroup Relations, Academic Press: London.

Tinsley, C.H. and Brett, J.M. (2001) 'Managing workplace conflict in the United States and Hong Kong', Organizational Behavior and Human Decision Processes 85(2): 360-381.

Tjosvold, D. and Sun, H. (2002) 'Understanding conflict avoidance: relationship, motivations, actions, and consequences', International Journal of Conflict Management 13(2): 142-164.

Tjosvold, D., Law, K.S. and Sun, H. (2003) 'Collectivistic and individualistic values: their effects on group dynamics and 
productivity in China', Group Decision and Negotiation 12(3): 243-263.

Triandis, H.C. (1995) Individualism and Collectivism, Westview Press: Boulder, CO.

Trubinsky, P., Ting-Toomey, S. and Lin, S-L. (1991) 'The influence of individualism-collectivism and self-monitoring on conflict styles', International Journal of Intercultural Relations 15(1): 65-84.

Van Dyne, L. and Lepine, I.A. (1998) 'Helping and voice extrarole behaviors: evidence of construct and predictive validity', Academy of Management Journal 41(1): 108-119.
Vollbrecht, J.L., Roloff, M.E. and Paulson, G.D. (1997) 'Coercive potential and face-sensitivity: the effects of authority and directives in social confrontation', International Journal of Conflict Management 8(3): 235-251.

Vroom, V.H. (1964) Work and Motivation, Wiley: New York.

Yang, K-S. (1981) 'Social orientation and individual modernity among Chinese students in Taiwan', Journal of Social Psychology 113(2): 159-170.

Zhou, J. and Martocchio, J.J. (2001) 'Chinese and American managers. Compensation award decisions: a comparative policy-capturing study', Personnel Psychology 54(1): 115-145.

\section{Appendix A. Qualitative responses}

\section{Chinese sample}

\begin{tabular}{|c|c|c|c|c|}
\hline Category & $\begin{array}{l}\text { Directness } \\
\text { score }\end{array}$ & Sample & $\begin{array}{l}\text { Colleague } \\
\text { sample (\%) }\end{array}$ & $\begin{array}{l}\text { Boss sample } \\
\text { (\%) }\end{array}$ \\
\hline Feel angry & 2 & $\begin{array}{l}\text { I feel angry, but will do nothing } \\
\text { I'm angry, may only talk to family and close } \\
\text { friends }\end{array}$ & 5 & 9 \\
\hline Support and cooperate & 2.5 & $\begin{array}{l}\text { I'll recognize the colleague's proposal, get to } \\
\text { know what to do next, and add my additional } \\
\text { suggestions } \\
\text { I will provide suggestions to the boss on how to } \\
\text { implement the plan }\end{array}$ & 8 & 8 \\
\hline Talk to other colleagues & 3 & $\begin{array}{l}\text { I'll talk to other colleagues and discuss what to } \\
\text { do next }\end{array}$ & 6 & 8 \\
\hline Report to VP & 6 & $\begin{array}{l}\text { Talk to VP and provide evidence and witnesses } \\
\text { that it was my idea }\end{array}$ & 17 & 4 \\
\hline $\begin{array}{l}\text { Do nothing right now but draw a } \\
\text { lesson for future actions }\end{array}$ & 2.5 & $\begin{array}{l}\text { Think of a better and more original proposal } \\
\text { Be calm, keep distance from the colleague who } \\
\text { stole my idea, but be active and do more } \\
\text { research on the plan } \\
\text { Say nothing but collect more data on my own } \\
\text { Do not tell others about my idea next time }\end{array}$ & 23 & 17 \\
\hline $\begin{array}{l}\text { Talk directly with the colleague/boss } \\
\text { who stole my idea }\end{array}$ & 7 & $\begin{array}{l}\text { I'Il talk directly with this colleague } \\
\text { I'Il invite him for coffee } \\
\text { Talk directly with the boss }\end{array}$ & 35 & 27 \\
\hline Do nothing & 1 & Nothing to do & 6 & \\
\hline Quit & 1 & Prepare to quit & & 1 \\
\hline $\begin{array}{l}\text { Focus on relationship and self- } \\
\text { promotion }\end{array}$ & 3 & $\begin{array}{l}\text { Congratulate the boss for the success of the } \\
\text { proposal }\end{array}$ & & 6 \\
\hline $\begin{array}{l}\text { Wait, observe, and try to figure out } \\
\text { what's going on }\end{array}$ & 2 & $\begin{array}{l}\text { Try to know the boss's motivation and next } \\
\text { action }\end{array}$ & & 13 \\
\hline $\begin{array}{l}\text { Talk to boss and demand recognition } \\
\text { for contributions to the plan }\end{array}$ & 7 & $\begin{array}{l}\text { Ask the boss to tell VP it was my idea and let me } \\
\text { be in charge of the implementation of the plan }\end{array}$ & & 8 \\
\hline Spread information & 5 & $\begin{array}{l}\text { In meetings, pretend that the colleague who } \\
\text { stole my idea was directed and advised by me }\end{array}$ & 8 & \\
\hline
\end{tabular}




\section{American sample}

\begin{tabular}{|c|c|c|c|c|}
\hline Category & $\begin{array}{l}\text { Directness } \\
\text { score }\end{array}$ & Sample & $\begin{array}{l}\text { Colleague } \\
\text { sample (\%) }\end{array}$ & $\begin{array}{c}\text { Boss sample } \\
\text { (\%) }\end{array}$ \\
\hline Report to VP first & 5 & I would... approach the VP and explain the situation & 10 & 3 \\
\hline Confront Roberts, then go to VP & 7 & $\begin{array}{l}\text { Discuss the issue with Roberts... Advise him that I will } \\
\text { meet with the VP and schedule him for the meeting... }\end{array}$ & 7 & 7 \\
\hline $\begin{array}{l}\text { Confront Roberts and VP } \\
\text { together }\end{array}$ & 7 & $\begin{array}{l}\text { Pull both Roberts and the (VP) aside and tell them the } \\
\text { truth about the ideas presented }\end{array}$ & 8 & \\
\hline Confront Roberts in private & 7 & $\begin{array}{l}\text { Approach Chris Roberts, voicing my displeasure with } \\
\text { his choice of action }\end{array}$ & 14 & 15 \\
\hline Communicate feelings & 6 & Confront my boss and indicate that it bothered me & 7 & \\
\hline $\begin{array}{l}\text { Make Roberts tell others it was } \\
\text { my idea }\end{array}$ & 7 & $\begin{array}{l}\text { Approach Roberts individually [and] tell him how } \\
\text { pissed off I was and if he had any spine that he would } \\
\text { give credit where it was due }\end{array}$ & 17 & 9 \\
\hline $\begin{array}{l}\text { Confront Roberts first, if needed } \\
\text { go to VP }\end{array}$ & 7 & $\begin{array}{l}\text { I must immediately confront Roberts... If he refuses to } \\
\text { (report that to the VP that it was my idea), I will have } \\
\text { to take the case to the VP }\end{array}$ & 7 & \\
\hline Confront and ask 'why'? & 7 & $\begin{array}{l}\text { I would confront Mr. Roberts to find out what his } \\
\text { motive was. I would want to know why he stole my } \\
\text { idea. }\end{array}$ & 19 & 28 \\
\hline $\begin{array}{l}\text { Confront and ask for public } \\
\text { announcement }\end{array}$ & 7 & $\begin{array}{l}\text { I would find out why he presented my idea. Then get } \\
\text { him to tell everyone that it was my idea }\end{array}$ & 4 & \\
\hline Confront during meeting & 7 & $\begin{array}{l}\text { I wouldn't wait until after the meeting. I would } \\
\text { confront Chris right then }\end{array}$ & 3 & \\
\hline Ask for credit in the future & 3 & $\begin{array}{l}\text { I would only ask that in the future, I be given proper } \\
\text { credit and full involvement }\end{array}$ & & 4 \\
\hline Threat & 7 & $\begin{array}{l}\text { I would find out what he was thinking! (And make it } \\
\text { clear that if he wasn't going to be honest and set } \\
\text { things right, then I would }\end{array}$ & & 4 \\
\hline Get more involved & 1 & $\begin{array}{l}\text { I would talk with Roberts after the meeting and } \\
\text { express my surprise at the timing of the [proposal] } \\
\text { I would then try to identify my role in the project as } \\
\text { [it] goes forward }\end{array}$ & & 7 \\
\hline Do research & 3 & $\begin{array}{l}\text { [I would] look for a paper trail to prove that I had been } \\
\text { working on the plan. Once established, confront } \\
\text { Roberts }\end{array}$ & & 3 \\
\hline Sneaky claim for credit & 4 & $\begin{array}{l}\text { I would discuss with Roberts about how positive the } \\
\text { VP of Marketing had been. Next, I would determine } \\
\text { our next steps }\end{array}$ & & 8 \\
\hline Build coalition & 4 & $\begin{array}{l}\text { I would enlist the support of others and present my } \\
\text { case to the...VP }\end{array}$ & 3 & \\
\hline Diagnose what happened & 1 & $\begin{array}{l}\text { Talk to Chris Roberts and try to find out how he came } \\
\text { up with these ideas. Then I would try to retrace my } \\
\text { steps to see who I talked to and figure out who would } \\
\text { have showed my ideas [to Chris] }\end{array}$ & 3 & \\
\hline Do nothing & 1 & [I would] wish him well on completion of the project & 6 & 4 \\
\hline
\end{tabular}




\section{About the authors}

Ray Friedman is the Brownlee O. Currey Professor of Management at the Owen Graduate School of Management, Vanderbilt University. He received his Ph.D. from the University of Chicago. His research has focused on conflict management, and more recently on Chinese-American differences in negotiation, conflict styles, and arbitrator decision-making.

Shu-Cheng Chi is a professor of organizational behavior at National Taiwan University. He received his Ph.D. from the State University of
New York at Buffalo. His current research interests include Chinese organizational behavior, conflict management, and the effects of social/cultural contexts in Taiwan or in China on processes within organizations.

Leigh Anne Liu is Assistant Professor of International Business at the Robinson College of Business, Georgia State University. She received her Ph.D. from Vanderbilt University. Her research passion centers on socially shared cognition in negotiation and interpersonal processes, and comparative organizational behavior in same and cross-cultural contexts. 